\title{
Antidiabetic Potentials of Diodia sarmentosa SW (Rubiaceae) Leaves on Alloxan-Induced Diabetic Rats
}

Elechi NA*, Okezie-Okoye C and Abo KA

Department of Pharmacognosy, Faculty of Pharmaceutical Sciences, University of Port Harcourt, Nigeria

DOI: $10.36348 /$ sjmps.2020.v06i09.006 $\quad$ | Received: 07.08.2020 | Accepted: 14.08 .2020 | Published: 30.09 .2020

*Corresponding author: Elechi NA

\section{Abstract}

This study has investigated the antidiabetic potential of the extracts of Diodia sarmentosa (Rubiaceae) leaves on alloxan induced diabetic Wistar rats. The leaves are used to treat diabetes and various other disease conditions in traditional medicine. In this study, the leaves were air-dried and pulverized. A $1 \mathrm{~kg}$ of the powdered leaves was extracted by maceration with n-hexane, chloroform and $70 \%$ methanol successively for three consecutive days, respectively. Phytochemical screening was conducted on the leaves using standard methods. Acute toxicity test was conducted on the rats by the Lorke's method. Diabetes was induced by the intraperitoneal injection of $120 \mathrm{mg} / \mathrm{kg}$ body weight of alloxan monohydrate to the rats. Results of the phytochemical screening showed the presence of cardiac glycosides, saponins, tannins, triterpenoids and carbohydrates. The acute toxicity test indicated the plant to be safe since no fatality was recorded on the rats even at the dose of $5000 \mathrm{mg} / \mathrm{kg}$ body weight. The n-hexane extract produced a peak significant $(\mathrm{p}<0.05)$ reduction of $75.3 \%$ in the blood glucose levels of the rats at day 7 , comparable to $82.38 \%$ reduction by the control drug, glibenclamide. The chloroform and aqueous methanol extracts did not exhibit significant reductions in blood glucose levels. This study suggests that the n-hexane extract of $D$. sarmentosa leaves possesses significant $(\mathrm{p}<0.05)$ antidiabetic activity. This tends to justify its use in ethnomedicine for the management of diabetes and its related conditions.

Keywords: Diodia sarmentosa, (Rubiaceae), Antidiabetic, Alloxan-induced diabetic Wistar rats.

Copyright @ 2020: This is an open-access article distributed under the terms of the Creative Commons Attribution license which permits unrestricted use, distribution, and reproduction in any medium for non-commercial use (NonCommercial, or CC-BY-NC) provided the original author and source are credited.

\section{INTRODUCTION}

Diabetes mellitus is a metabolic disorder of insulin characterized by hyperglycaemia and alterations in carbohydrate, fat and protein metabolism [1]. It causes significant morbidity and mortality due to microvascular and macrovascular complications [2]. In a review article by Jung, et al., [3], it was reported that traditional medicines from readily available medicinal plants offer a great potential for the discovery of new antidiabetic drugs. And that most of the plant extracts exhibited hypoglycemic, hypolipidemic, and antioxidant effects in animals as well as in humans, which may be useful in treating diabetes and its complications. According to this report, the chemical constituents with the greatest effect on post-prandial hyperglycaemia include insulin, amylin analogues, and glucosidase inhibitors.

It has also been suggested that in hyperglycaemia associated with diabetes, the use of aldose reductase inhibitors is useful in the treatment of diabetic complications [4]. The identified plant-derived aldose reductase inhibitors include the isoquinoline alkaloids, berberine chloride and palmatine iodide. Aldose reductase catalyzes the reduction of glucose to sorbitol. Sorbitol does not readily diffuse across cell membranes, and when it accumulates it produces osmotic stresses on the cells by drawing water into them. The intracellular accumulation of sorbitol has been implicated in the chronic complications of diabetes, especially in the microvascular damage to the retina, kidney, and nerves [5-7]. Some plant extracts have been reported to exert antidiabetic effects by stimulating insulin release from the pancreatic beta cells. These plants include the aqueous leaf extract of Aegle marmelos, and the ethyl ether extract of Allium sativum [8]; the seeds of Acacia arabica [9]; and the aqueous extract of Agrimony eupatoria [10].

The leaves of Diodia sarmentosa have been reported to be used by traditional medicine practitioners in Southern Nigeria to manage diabetes mellitus. It is a straggling perennial evergreen plant with alternate leaf arrangement with climbing stems up to about $3 \mathrm{~m}$. The 
leaves are opposite ovate to ovate lanceolate. The inflorescence consists of several white flowers clustered in the leaf axils. It can be found in gallery forest, grassy places, in the light shade of big trees, humus soil, old secondary swampy forest, on the roadside of secondary forest, in swampy open places and also in cultivated fields and bush fallow re-growths in the forest zones [11]. It is widespread in tropical Africa, Asia and America.

In Nigeria, D. sarmentosa leaves are also used for treating eczema; its juice is used to stop bleeding, and the plant is used as anti-abortifacient [12]. In addition, the ethanol extract of the whole plant was reported to have anti-ulcer activity [13]. Three iridoid glycosides, asperuloside, geniposidic acid and asperulosidic acid; a coumarin glycoside, scopolin; and 6 flavonoids, rutin, kaempferol-3-0-rutinoside, quercitrin, astragalin, isoquercitrin and quercetin were isolated from the methanolic extract of the whole plant of another species, D. teres [14]. The present study aims at investigating the in vivo antidiabetic potential of Diodia sarmentosa in alloxan-induced diabetic rats.

\section{Materials \& Methods}

Plant material: The fresh leaves of Diodia sarmentosa SW (Rubiaceae) were collected in Choba, Port Harcourt and authenticated by a taxonomist, Dr. M. Bassey in the Department of Botany, University of Uyo, Uyo, with a Herbarium number, UUH032/15.

Experimental animals: Healthy male and female Wistar albino rats weighing between 150-200g were used for this study. The rats were fed with standard feed and water ad libitum, throughout the study [15].

Phytochemical screening: Phytochemical screening of the leaves of the plant was carried out using standard procedures $[16,17]$.

Extraction of plant material: A $1 \mathrm{~kg}$ of the dried and pulverized leaves was extracted successively with n-hexane, chloroform and $70 \%$ aqueous methanol. Each of the filtrates was evaporated to dryness in vacuo, in a rotary evaporator to obtain the respective extracts. Each of these extracts was then used for the biological assay.
Acute toxicity test: 18 animals of both sexes were used in the determination of the acute toxicity of the extract as previously reported [18].

Induction of diabetes mellitus: Hyperglycaemia was achieved by intraperitoneal administration of $120 \mathrm{mg} / \mathrm{kg}$ body weight dose of alloxan monohydrate [19]. After 4 days, animals showing blood glucose levels above $200 \mathrm{mg} / \mathrm{dl}$ were considered diabetic, and selected for the study.

Treatment schedule: The rats were divided into 6 groups of five rats each. Group 1 was normal control rats (non-diabetic, untreated); Groups 2-6 were diabetic rats. Group 2 were treated with glibenclamide, $2.5 \mathrm{mg} / \mathrm{kg}$ body weight; Group 3 were diabetic untreated; Groups 4-6 were each treated with one of the three extracts at $1000 \mathrm{mg} / \mathrm{kg}$ b.w., respectively

Day 1: Basal blood glucose levels at zero time were determined (with glucometer) before the oral treatment. The drug and extracts were administered immediately to rats in the appropriate cages. Animals in groups 1 and 3 were not treated. Blood glucose levels were determined at 60 minute intervals for the next 180 minutes as previously described [19]. Days 2-7: The blood glucose levels were taken once daily, 2 hours after the administration of drug and extracts.

\section{Statistical Analysis}

All data obtained from the study were expressed as mean \pm SEM. Percentage reduction in blood glucose levels were calculated. Statistical analysis was done by ANOVA using SPSS package version 2.0.The significant difference $(p<0.05)$ between the treated and untreated control animals was established by student's t-test.

\section{RESULTS}

Phytochemical screening: The results in Table 1 show the presence of cardiac glycosides, tannins, saponins, steroidal and triterpenoid nuclei. Alkaloids, anthraquinones, flavonoids and cyanogenic glycosides are absent. 
Table-1: Results for the phytochemical screening of the dried leaf extract of Diodia sarmentosa

\begin{tabular}{|c|c|c|}
\hline $\mathbf{S} / \mathbf{N}$ & TESTS FOR METABOLITES & INFERENCE \\
\hline 1 & Tannins (Ferric chloride test) & + \\
\hline 2 & Phlobatannins & - \\
\hline 3 & $\begin{array}{l}\text { Alkaloids: a. Dragendorff's reagent } \\
\text { b. Mayer's reagent } \\
\text { c. Hager's reagent }\end{array}$ & $\begin{array}{l}- \\
- \\
-\end{array}$ \\
\hline 4 & Anthraquinones (Borntrager's test) & - \\
\hline 5 & $\begin{array}{l}\text { Carbohydrate (Molisch's test) } \\
\text { Reducing Sugar test (Fehling's reagents) }\end{array}$ & $\begin{array}{ll}+ \\
+ \\
-\end{array}$ \\
\hline 6. & $\begin{array}{l}\text { Saponins: a. Frothing test } \\
\text { b. Emulsion test } \\
\text { c. Haemolysis test }\end{array}$ & $\begin{array}{l}+ \\
+ \\
+\end{array}$ \\
\hline 7. & $\begin{array}{l}\text { Steroids (Salkowski test) } \\
\text { Triterpenoids (Liebermann-Burchard test) }\end{array}$ & $\begin{array}{l}+ \\
+ \\
+\end{array}$ \\
\hline 8. & $\begin{array}{c}\text { Cardiac glycosides: a. Deoxy sugars (Keller-Kiliani test) } \\
\text { b. Cardenolides (Kedde's test) }\end{array}$ & $\begin{array}{ll}+ \\
-\end{array}$ \\
\hline 9. & Cyanogenic glycosides & - \\
\hline 10. & $\begin{array}{c}\text { Flavonoids: a. Sodium hydroxide test } \\
\text { b. Shinoda test }\end{array}$ & - \\
\hline
\end{tabular}

Key: + = positive (present); - = negative (absent).

Table-2: Results of the acute toxicity tests on the crude aqueous methanol extract of Diodia sarmentosa

\begin{tabular}{|l|l|l|l|}
\hline DAY & DOSE, mg/kg body wt. & SURVIVAL & DEATHS \\
\hline 1 & 10 & $3 / 3$ & $0 / 3$ \\
& 100 & $3 / 3$ & $0 / 3$ \\
& 1000 & $3 / 3$ & $0 / 3$ \\
\hline 2 & 1600 & $3 / 3$ & $0 / 3$ \\
& 2900 & $3 / 3$ & $0 / 3$ \\
& 5000 & $3 / 3$ & $0 / 3$ \\
\hline
\end{tabular}

\section{Acute toxicity test}

As shown in Table 2, no death was recorded among the animals even at the highest dose of $5000 \mathrm{mg} / \mathrm{kg}$ body weight, on Day 2.

Table-3: Effect of the various extracts of the leaf of Diodia sarmentosa on blood glucose levels (mg/dl) of alloxan-induced diabetic rats (Day 1)

\begin{tabular}{|l|l|l|l|l|l|}
\hline TREATMENT & DOSE (mg/kg & \multicolumn{4}{l|}{ DAILY BLOOD GLUCOSE LEVELS (mg/dl) } \\
\cline { 3 - 6 } & body wt.) & $\mathbf{0}$ min. & $\mathbf{6 0}$ min & $\mathbf{1 2 0}$ min. & $\mathbf{1 8 0 ~ m i n . ~}$ \\
\hline n-Hexane extract & 1000 & $530.0 \pm 47.51$ & $\begin{array}{l}373.67 \pm 18.28 \\
(28.1)\end{array}$ & $385.57 \pm 2.74$ & $\begin{array}{l}424.3 \pm 16.67 \\
(19.58)\end{array}$ \\
\hline Chloroform extract & 1000 & $389.0 \pm 7.23$ & $421.33 \pm 6.0$ & $522.67 \pm 17.68$ & $543.67 \pm 26.56$ \\
\hline Aq. Methanol extract & 1000 & $513.33 \pm 2.58$ & $516.00 \pm 2.79(0.83)$ & $460.67 \pm 19.46$ & $490.33 \pm 29.17(7.08)$ \\
\hline Glibenclamide & 2.5 & $255.00 \pm 9.76$ & $217.33 \pm 8.36(58.23)^{*}$ & $150.33 \pm 12.28(38.5)^{*}$ & $186.0 \pm 16.13(64.7)^{*}$ \\
\hline Diabetic untreated rats & - & $531.00 \pm 5.50$ & $520.33 \pm 3.78$ & $370.0 \pm 15.20$ & $527.67 \pm 17.07$ \\
\hline Normal rats & - & $118.00 \pm 3.79$ & $118.00 \pm 3.79$ & $128.00 \pm 4.26$ & $119.00 \pm 6.11$ \\
\hline
\end{tabular}

Each value is represented as mean \pm S.E.M, where $n=5 ; *$ represent the values that are significantly $(\mathrm{p}<0.05)$ different compared to the diabetic untreated. The figures in parenthesis represent the $\%$ decrease in blood glucose levels.

Table-4: Results of the effects of the various extracts of Diodia sarmentosa on fasting blood glucose levels of alloxan-induced diabetic rats (Day2-7)

\begin{tabular}{|l|l|l|l|l|l|l|}
\hline \multirow{2}{*}{$\begin{array}{l}\text { TREATMENT } \\
\text { (mg/kg b.w) }\end{array}$} & \multicolumn{6}{|l|}{ DAILY BLOOD GLUCOSE LEVELS (mg/dl) } \\
\cline { 2 - 7 } n-Hexane (1000) & DAY 2 & DAY 3 & DAY 4 & DAY 5 & DAY 6 & DAY 7 \\
& $745.67 \pm$ & $353.0 \pm$ & $309.0 \pm 19.29$ & $194.0 \pm 3.15$ & $141.33 \pm 8.52$ & $124.67 \pm 1.48$ \\
$(73.1) *$ & $29.19(30.73)^{*}$ & $(43.1)^{*}$ & $(63.35)^{*}$ & $(73.67)^{*}$ & $(75.23)^{*}$ \\
\hline Chloroform (1000) & $556.67 \pm 9.67$ & $597.33 \pm 7.21$ & $548.6 \pm 27.79$ & $564.33 \pm 21.8$ & $572.67 \pm 22.0$ & $534.37 \pm 24.9$ \\
\hline Aq. Methanol & $399.00 \pm 32.0$ & $402.00 \pm 42.7$ & $434.00 \pm 22.4$ & $422.67 \pm 22.2$ & $311.33 \pm 9.36$ & $406.67 \pm 3.88$ \\
$(1000)$ & $(22.87)$ & $(21.11)$ & $(20.22)$ & $(20.15)$ & $(41.9)^{*}$ & $(19.2)$ \\
\hline Glibenclamide & $158.3 \pm 8.68$ & $124.6 \pm 1.39$ & $113.67 \pm 8.91$ & $105.0 \pm 1.62$ & $107.3 \pm 8.45$ & $88.67 \pm 6.67$ \\
$(2.5)$ & $(69.39)^{*}$ & $(75.52)^{*}$ & $(79.10)^{*}$ & $(80.16)^{*}$ & $(80.0)^{*}$ & $(82.38)^{*}$ \\
\hline Diabetic untreated & $517.3 \pm 19.1$ & $509.5 \pm 9.97$ & $544.0 \pm 17.95$ & $529.3 \pm 10.3$ & $536.6 \pm 5.54$ & $503.3 \pm 9.61$ \\
\hline Normal rats & $109.0 \pm 3.6$ & $100.3 \pm 3.33$ & $114.0 \pm 7.55$ & $113.0 \pm 7.42$ & $118.0 \pm 7.42$ & $120.6 \pm 7.33$ \\
\hline
\end{tabular}

Each value is represented as mean \pm S.E.M, where $n=5 ; *$ represent the values that are significantly $(\mathrm{p}<0.05)$ different compared to the diabetic untreated. The figures in parenthesis represent the $\%$ decrease in blood glucose levels. 


\section{DISCUSSION}

Table 2 shows that even at the highest dose of $5000 \mathrm{mg} / \mathrm{kg}$ body weight there was no mortality of the tested rats. This implies that the extract is safe [18], and that its use in ethnobotany as an oral medication for treating dysentery is not deleterious to health at these tested dose ranges [20]. Table 3 shows that none of the extracts demonstrated significant reduction in blood glucose levels after 180 minutes on Day 1 of the study. However, the standard drug, glibenclamide showed a significant $(\mathrm{p}<0.05) 64.7 \%$ reduction at 180 minutes. This suggests that the extracts may not be effective in providing an immediate action against hyperglycaemia. In Table 4, the n-hexane extract produced a peak significant $(p<0.05)$ reduction of $75.3 \%$ in blood glucose at day 7 , when compared to the diabetic untreated group of rats. This is comparable to the peak reduction of $82.3 \%$ exhibited by the standard drug, glibenclamide. However, the chloroform and aqueous methanol extracts did not produce significant reductions. There are more than 400 plants with antidiabetic properties and most of these plants contain flavonoids, carotenoids, terpenoids and alkaloids which have frequently been implicated in having this activity $[10,21,22,23$, ]. The phytochemical compounds found to be present in the leaf of $D$. sarmentosa include cardiac glycosides, saponins, tannins, triterpenoids and carbohydrates (Table 1). These constituents may be responsible in part for the observed significant activity of the n-hexane extract of the leaf of this plant, either singly, or in synergy with one another [24].

\section{CONCLUSION}

The results of this study show that the nhexane leaf extract of $D$. sarmentosa possesses antidiabetic properties. This tends to justify its use in ethnomedicine for the management of diabetes mellitus.

\section{Further work}

Further work is on-going to isolate and characterize the active compounds responsible for this reported activity.

\section{No conflict of interest}

The authors do hereby affirm that there are no conflicts of interest on this work.

\section{REFERENCES}

1. Kumar, G.P., Kumar, S., \& Subremanian, P.S. (2006). Antidiabetic activity of fruits of terminalia chebula on streptozotocin induced diabetes. $J$. Health Sci., 52: 283-291.

2. Patel, D.K., Kumar, R. Prasad, S.K., Sairam, K., \& Hemalathas, S. (2011). Antidiabetic and in vitro antioxidant potential of Hybanthus enneaspermus (Linn.) F. Muell in streptozotocin-induced diabetic rats. Asian Pac J Trop Biomed, 1(4): 316-322.
3. Jung, M., Park, M., Lee, H.C., Kang, Y-H, Kang, E. S., \& Kim, S.K. (2006). Antidiabetic agents from medicinal plants. Current Medicinal Chemistry, 13: 1203-18.

4. Lee, H. S. (2002). Rat lens Aldose Reductase inhibitory activities of Coptis japonica root-derived isoquinoline alkaloids. J. Agric. Food Chem, 50(24): 7013-7016.

5. Wikipedia, accessed https://en.m.wikipedia.org, $30^{\text {th }}$ June, 2020.

6. Behl, T., Kaur, I., \& Kotwani, A. (2016). Implication of oxidative stress in progression of diabetic retinopathy. Survey of Ophthalmology, 61(2): 187-96.

7. Jedziniak, J.A., Chylack, L.T., Cheng, H.M., Gillis, M.K., Kalustian, A.A., \& Tung, W.H. (1981). The sorbitol pathway in the human lens: aldose reductase and polyol dehydrogenase. Investigative Ophthalmology and Visual Science, 20(3): 314-26.

8. Ayodhya, S., Kasum, S., \& Anjali, S. (2010). Hypoglycaemic activity of different extracts of various herbal plants. Int J Ayurvedia Res Pharm, 1(1): 212-224.

9. Singh, L.W. (2011). Traditional medicinal plants of Manipur as antidiabetic. J med plants Res, 5(5): 677-687.

10. Bnouham, M., Ziyyat, A., Mekhfi, H., Tahri, A., \& Legssyer, A. (2006). Medicinal plants with potential antidiabetic activity - A review of ten years of herbal medicine research. Int J Diabetes \& Metabolism, 14: 1-25.

11. Plants. Jstor, accessed https://plants.jstor.org, $30^{\text {th }}$ June, 2020.

12. Etukudo, I. (2003). Ethnobotany: Conventional and traditional use of plants. First edition, Verdict Press Ltd., Uyo, Nigeria, 24-35.

13. Sandhya, S., Venkata, R.K., Vinod, K.R., Swapna, R., \& Asia, B. (2013). Scope of medicinal flora as effective anti-ulcer agents. African Journal of Plant Science, 7(11): 504-512.

14. Lee, J. H., Ku, C.H., Baek, N, I., Kim, S.H., Park, H.W., \& Kim, D.K. (2004). Phytochemical constituents from Diodia teres. Archives of Pharmacal Research, 27(1): 40-43.

15. Abo, K.A., \& Lawal, I.O. (2013). Antidiabetic Activity of Physalis angulata extracts and fractions in Alloxan-induced Diabetic Rats. J. Adv Sci Res, 4(3): 32-36.

16. Harbourne, J.B. (1998). Phytochemical Methods, $3^{\text {rd }}$ ed. Chapman and Hall, London, p.84-131.

17. Sofowora, A. (1993). Medicinal plants and traditional medicine in Africa. $2^{\text {nd }}$ ed. Spectrum Books Ltd., Sunshine House, Ibadan, Nigeria, 191289.

18. Lorke, D. (1983). A new approach to practical Acute Toxicity Test. Arch. Toxicol. 275-287.

19. Abo, K.A., \& Jimoh, B.T. (2004). Antihyperglycaemic potential of stem bark of Bauhinia 
monandra Kurz. In rats Nig. J. Nat. Prod. And Med, 8:48-50.

20. Soladoye, M. O., Osipitan, A. A., Sonibare, M. A., \& Chukwuma, E. C. (2010). From 'Vagabonds' to ethnobotanical relevance: weeds of the campus sites of Olabisi Onabanjo University, Ago-Iwoye, Nigeria. Ethnobotanical Leaflets, 2010(4), 17.

21. Malviya, C., Jain, S., \& Malviya, S. (2010). Antidiabetic potential of medicinal plants. Acta. Pol. Pharm, 67(2): 113-118.

22. Kumar, R., Kumar, P.D., Prasad, S.K., Sairam, K., \& Hemalatha, S. (2011). Antidiabetic activity of alcoholic leaves extract of Alangium lamarckii Thwaites on streptozotocin-nicotinamide induced Type 2 diabetic rats. Asian Pac. J. Med, 4(11): 904-909.

23. Okokon, J.E., Udoh, A.E., Amazu, L., \& Frank, S.G. (2012). Anti-inflammatory and analgesic activities of Melanthera scandens. Asian Pac J Trop Biomed, 2(2): 144-148.

24. Patil, R.N., Patil, R.Y., Ahirwar, B., \& Ahirwar, D. (2011). Evaluation of antidiabetic and related actions of some Indian medicinal plants in diabetic rats. Asian Pac J Trop Med, 4(1): 20-23. 